\title{
Clinical Effectiveness of Incentive Spirometry for the Prevention of Postoperative Pulmonary Complications
}

\author{
Adam E M Eltorai MSc, Ashley L Szabo MD, Valentin Antoci Jr MD PhD, \\ Corey E Ventetuolo MD MSc, Jack A Elias MD, Alan H Daniels MD, and \\ Dean R Hess PhD RRT FAARC
}

\author{
Introduction \\ History \\ Device Types \\ Clinical Application \\ Systematic Reviews \\ Clinical Practice Guidelines \\ Why Have the Studies Been Negative? \\ Poor Methodology \\ Adherence \\ Perhaps IS Is Not Effective \\ Summary
}

\begin{abstract}
Incentive spirometry (IS) is commonly prescribed to reduce pulmonary complications, despite limited evidence to support its benefits and a lack of consensus on optimal protocols for its use. Although numerous studies and meta-analyses have examined the effects of IS on patient outcomes, there is no clear evidence establishing its benefit to prevent postoperative pulmonary complications. Clinical practice guidelines advise against the routine use of IS in postoperative care. Until evidence of benefit from well-designed clinical trials becomes available, the routine use of IS in postoperative care is not supported by high levels of evidence. Key words: incentive spirometry; review of evidence; use procedure; respiratory care; postoperative care; compliance; hospital-acquired pneumonia; atelectasis. [Respir Care 2018;63(3):347-352. (c) 2018 Daedalus Enterprises]
\end{abstract}

\section{Introduction}

Incentive spirometry (IS) is widely prescribed to prevent postoperative pulmonary complications. In the United

Drs Antoci Jr, Ventetuolo, Elias, Daniels, and Mr Eltorai are affiliated with the Warren Alpert Medical School of Brown University, Providence, Rhode Island. Dr Szabo is affiliated with The Cleveland Clinic, Cleveland, Ohio. Dr Hess is affiliated with Massachusetts General Hospital, Boston, Massachusetts.

Mr Eltorai has disclosed a relationship with Springer and Lippincott Williams \& Wilkins. Dr Hess has disclosed relationships with Philips Respironics, Ventec Life Systems, Jones and Bartlett, McGraw-Hill, UpToDate, and the American Board of Internal Medicine. Dr Daniels has
States, respiratory therapists and nurses are responsible for instruction and monitoring of patients receiving IS. ${ }^{1}$ Intermittent reassessment of patient performance after initial instruction is recommended. However, the amount of time

disclosed relationships with DePuy, Globus Medical, Orthofix, Inc., Springer, and Stryker. The other authors have disclosed no conflicts of interest.

Correspondence: Adam E M Eltorai MSc, Warren Alpert Medical School of Brown University, 70 Ship Street, Providence, RI 02903. E-mail: adam_eltorai@brown.edu.

DOI: $10.4187 /$ respcare. 05679 
that providers spend on IS-related activities has not been reported, nor have optimal use procedures been established. In this article, we review the current state of IS and question its role in the management of postoperative pulmonary complications.

\section{History}

In the 1960s, intermittent positive-pressure breathing (IPPB) was commonly used to prevent postoperative pulmonary complications. However, IPPB came under scrutiny at the Sugarloaf Conference, where it was determined that there was not sufficient evidence to support its use..$^{2,3}$ Coincidental with the criticism of IPPB, the incentive spirometer was introduced by Bartlett et $\mathrm{al}^{4}$ after observations that yawning might generate pulmonary benefits for postoperative patients. Deciding that it was the sustained inspiration of yawning that yielded the benefit, the group constructed a device to coach patients to emulate a yawning-like sustained maximal inspiration in an effort to prevent atelectasis. The inventors' early data from postoperative patients performing sustained maximal inspiration demonstrated improvement in ventilation/perfusion mismatch and alveolar- $\mathrm{P}_{\mathrm{aO}}$ gradient, the latter suggestive of alveolar inflation and subsequent reduction in intrapulmonary shunt. When sustained maximal inspirations were repeated each hour, $\mathrm{P}_{\mathrm{aO}_{2}}$ levels remained near normal. These preliminary findings came to define the anticipated physiologic effects of IS.

In 1973, the Bartlett-Edwards IS device was introduced to incentivize deep breathing by providing visual light feedback when patients achieved their inspiratory target volume. ${ }^{4}$ In 1975, the Spirocare device further enhanced the electronic IS visual feedback by putting the display lights on a scale indicating increasingly larger inspiratory volumes, attempting to gamify patient engagement and adherence. ${ }^{5}$ These electronic IS devices were in use for many years but have been replaced by less expensive, disposable units.

\section{Device Types}

IS devices are either flow-oriented or volume-oriented. Flow-oriented IS devices consist of a chamber with 3 interconnected columns in which lightweight plastic floats are seated. The chamber is connected to a flexible tube with a mouthpiece through which the patient inhales, attempting to raise the floats through inspiratory flow created by negative intrathoracic pressure. Volume-oriented IS devices consist of a flexible tube with a mouthpiece connected to a chamber that has volume measurements displayed. When the patient inhales, a piston in the chamber rises to the maximum volume of air displaced. Clinical
Table 1. Variety of Clinical Approaches for Incentive Spirometry Use

\begin{tabular}{|c|c|}
\hline Parameter & Suggestion \\
\hline Frequency of sessions & $\begin{array}{l}\text { Every } 10 \min ^{1} \\
\text { Every } 1 \mathrm{~h}^{6} \\
\text { Every } 2 \mathrm{~h}^{6} \\
2 \text { times } / \mathrm{d}^{7} \\
4 \text { times } / \mathrm{d}^{8-10} \\
5 \text { times } / \mathrm{d}^{11-14} \\
12 \text { times } / \mathrm{d}^{15,16} \\
4 \text { times } / \mathrm{h}^{20} \\
3 \text { times } / \mathrm{h}^{21} \\
\text { Every } 4 \mathrm{~h}^{17-19} \\
10 \text { times } / \mathrm{h}^{22} \\
30 \text { times } / \mathrm{h}^{23}\end{array}$ \\
\hline Target inspiratory volume & $\begin{array}{l}50-70 \% \text { of preoperative vital } \\
\text { capacity }{ }^{24} \\
1,400-1,770 \mathrm{~mL}^{25} \\
200-2,000 \mathrm{~mL}^{26} \\
\text { Maximal inspiration above residual } \\
\text { volume }^{17}\end{array}$ \\
\hline $\begin{array}{l}\text { Number of breaths per } \\
\text { session }\end{array}$ & $\begin{array}{l}3^{19} \\
3-5^{14} \\
5^{18} \\
10^{16} \\
15^{25,27} \\
20^{28}\end{array}$ \\
\hline Duration of breath holds & $\begin{array}{l}5 \mathrm{~s}^{8-11,17,18,20} \\
3 \mathrm{~s}^{22} \\
\text { For as long as possible }{ }^{12}\end{array}$ \\
\hline $\begin{array}{l}\text { Perioperative incentive } \\
\text { spirometry use }\end{array}$ & $\begin{array}{l}\text { The first } 3 \mathrm{~d} \text { after surgery } \\
\text { The first } 4 \mathrm{~d} \text { after surgery } \\
\text { S5 } \\
\text { Starting } 4-72 \mathrm{~h} \text { after surgery }{ }^{1} \\
\text { Both preoperatively and during the } \\
\text { first } 5 \text { postoperative } \\
\text { days }{ }^{14,16,17,19,24} \\
\text { For } 3 \mathrm{~d} \text { after surgery }{ }^{31} \\
\text { For } 5 \mathrm{~d} \text { after surgery } \\
\text { Beginning } 1 \mathrm{~h} \text { after surgery for the } \\
\text { next } 3 \mathrm{~d}^{10,29} \\
\text { Beginning } 4 \mathrm{~h} \text { after extubation }{ }^{14}\end{array}$ \\
\hline Graduated use procedures & $\begin{array}{l}\text { Increasing inspiratory target volume } \\
\text { Increasing both volume and breath- } \\
\text { hold duration }{ }^{26} \\
\text { Decreasing frequency }^{18}\end{array}$ \\
\hline
\end{tabular}

practice guidelines suggest that volume-oriented devices are preferable due to lower imposed work for breathing. ${ }^{1}$

\section{Clinical Application}

A variety of clinical approaches for IS have been suggested (Table 1). Indeed, there seems to be no standardization of approach. IS has been recommended to be performed every $10 \mathrm{~min},{ }^{1}$ hourly, ${ }^{6}$ every $2 \mathrm{~h},{ }^{6} 2$ times per day, ${ }^{7} 4$ times per day, ${ }^{8-10} 5$ times per day, ${ }^{11-14} 12$ times per 
day, ${ }^{15,16}$ every 4 h, ${ }^{17-19} 4$ times per hour, ${ }^{20} 3$ times per hour, ${ }^{21} 10$ times per hour, ${ }^{22}$ or 30 times per hour. ${ }^{23}$ Target inspiratory volume has been set at $50-70 \%$ of preoperative vital capacity, ${ }^{24}$ at $1,400-1,770 \mathrm{~mL},{ }^{25}$ at $200-$ $2,000 \mathrm{~mL},{ }^{26}$ or at maximal inspiration above residual volume. ${ }^{17}$ Patients have been instructed to complete $3,{ }^{19} 3-5,{ }^{14}$ $5,{ }^{18} 10,{ }^{16} 15,,^{25,27}$ or 20 breaths per session..$^{28}$ The recommended duration of end-inspiratory breath-hold has been $5 \mathrm{~s},{ }^{8-11,17,18,20} 3 \mathrm{~s},{ }^{22}$ or for as long as possible. ${ }^{12}$ IS has been prescribed for the first $3 \mathrm{~d}^{44}$ or $4 \mathrm{~d}^{45}$ after surgery, starting 4-72 $\mathrm{h}$ after surgery, ${ }^{1}$ both preoperatively and during the first 5 postoperative days, ${ }^{14,16,17,19,24}$ for $3 \mathrm{~d}^{31}$ or $5 \mathrm{~d}^{30}$ after surgery, beginning $1 \mathrm{~h}$ after surgery and continuing for the next $3 \mathrm{~d},{ }^{10,29}$ or starting $4 \mathrm{~h}$ after extubation. ${ }^{14}$ Some studies report changing the use procedure during the hospital course, including increasing inspiratory target volume, ${ }^{9}$ increasing both volume and breath-hold duration, ${ }^{26}$ and decreasing frequency. ${ }^{18}$

\section{Systematic Reviews}

Thomas and McIntosh ${ }^{32}$ assessed the efficacy of IS, IPPB, and deep-breathing exercises in the prevention of postoperative pulmonary complications in patients undergoing upper abdominal surgery. The odds ratio for the occurrence of pulmonary complications for IS versus no physical therapy was 0.44 in favor of IS. The odds ratio for deep-breathing exercises versus no physical therapy was 0.43 in favor of deep-breathing exercises. The authors concluded that IS and deep-breathing exercises appear to be more effective than no therapy to prevent postoperative pulmonary complications, but evidence is lacking to support a significant difference between the modalities.

Overend et $\mathrm{al}^{33}$ conducted a systematic review on the use of IS for preventing postoperative pulmonary complications. In 35 of 46 included studies, they were unable to accept the stated conclusions due to flaws in methodology. Appraisal of the 11 remaining studies found that in 10 studies there was no positive short-term effect of IS after cardiac or abdominal surgery. In the only supportive study, IS, deep breathing, and IPPB were equally more effective than no treatment in preventing postoperative pulmonary complications after abdominal surgery. They concluded that the evidence does not support the use of IS to decrease the incidence of postoperative pulmonary complications after cardiac or upper abdominal surgery.

Carvalho et $\mathrm{al}^{34}$ conducted a systematic review of 30 studies (14 abdominal surgery, 13 cardiac surgery, and 3 thoracic surgery, including a total of 3,370 subjects). Five studies ( 3 abdominal surgery, 1 cardiac surgery, and 1 thoracic surgery) compared the effect of the IS with a control group of no intervention, and no difference was detected in the evaluated outcomes. The authors concluded that there was no evidence to support the use of IS in the management of surgical subjects.

A Cochrane review limited to subjects following coronary artery bypass graft included 592 subjects from 7 studies. ${ }^{35}$ There was no evidence of a difference between groups in the incidence of pulmonary complications with IS and treatment with physical therapy, positive-pressure breathing techniques, active cycle of breathing, or preoperative patient education. Subjects treated with IS had worse pulmonary function and arterial oxygenation compared to those treated with positive-pressure breathing. There was no improvement in the muscle strength with IS. The authors concluded that there was no evidence of benefit from IS in reducing postoperative pulmonary complications and in decreasing the negative effects on pulmonary function in patients undergoing coronary artery bypass graft.

Another Cochrane review assessed the effect of IS on postoperative pulmonary complications and mortality in adults undergoing upper abdominal surgery. ${ }^{36}$ They included 12 studies with a total of 1,834 subjects, and they were able to include data from 1,160 subjects in the metaanalysis. There were 4 trials (152 subjects) that compared the effects of IS with no respiratory treatment, with no significant difference in postoperative pulmonary complications. In 2 trials (194 subjects), IS was compared with deep-breathing exercises, with no significant effect of IS. In 2 trials (946 subjects) that compared IS with other chest physiotherapy, there was again no significant effect of IS. The authors concluded that there is low-quality evidence regarding the lack of effectiveness of incentive spirometry for prevention of postoperative pulmonary complications after upper abdominal surgery.

Agostini and Singh ${ }^{37}$ conducted a systematic review of IS after thoracic surgery. They concluded that physiological evidence suggests IS may be appropriate for lung re-expansion after major thoracic surgery. On the basis of sparse literature, postoperative physiotherapy regimes with or without the use of IS appeared effective after thoracic surgery compared with no physiotherapy. Interestingly, the same group ${ }^{30}$ did a later randomized, controlled trial, where they reported that IS did not improve overall recovery of lung function, frequency of postoperative pulmonary complications, or stay.

Subsequent to the publication of these systematic reviews, Cassidy et $\mathrm{al}^{25}$ reported the result of a program designated by the acronym I COUGH, which emphasizes incentive spirometry, coughing, deep breathing, oral care (eg, brushing teeth and using mouthwash twice daily), understanding (ie, patient and family education), getting out of bed at least 3 times daily, and head of bed elevation. Implementation of this protocol resulted in a reduction in postoperative pneumonia and unplanned intubations. Unfortunately, the individual elements of 
Table 2. Recommendations From the 2011 American Association for Respiratory Care Clinical Practice Guidelines on Incentive Spirometry

1. Incentive spirometry alone is not recommended for routine use in the preoperative and postoperative setting to prevent postoperative pulmonary complications.

2. It is recommended that incentive spirometry be used with deepbreathing techniques, directed coughing, early mobilization, and optimal analgesia to prevent postoperative pulmonary complications.

3. It is suggested that deep-breathing exercises provide the same benefit as incentive spirometry in the preoperative and postoperative setting to prevent postoperative pulmonary complications.

4. Routine use of incentive spirometry to prevent atelectasis in patients after upper-abdominal surgery is not recommended.

5. Routine use of incentive spirometry to prevent atelectasis after coronary artery bypass graft surgery is not recommended.

6. It is suggested that a volume-oriented device be selected as an incentive spirometry device.

From Reference 1.

the bundle were not tested alone, and thus it is not possible to know the extent to which IS contributed to the improved outcomes.

In 2017, Pantel et al ${ }^{38}$ reported the results of a randomized clinical trial that compared the use of postoperative IS to no use of IS after bariatric surgery. Postoperative IS did not demonstrate any effect on postoperative hypoxemia or postoperative pulmonary complications. Interestingly, although IS was prescribed for use 10 times per hour, the adherence rate was much lower at about 4 times per day on the first postoperative day and 10 times per day on the second postoperative day.

\section{Clinical Practice Guidelines}

Several clinical practice guidelines from the American Association for Respiratory Care have addressed the clinical application of IS. These guidelines do not support the use of IS to prevent postoperative pulmonary complications. From the guidelines published in 2011, ${ }^{1}$ IS alone is not recommended for routine use in the preoperative and postoperative setting to prevent postoperative pulmonary complications. Routine use of IS to prevent atelectasis in patients after upper-abdominal surgery is not recommended, and routine use of IS to prevent atelectasis after coronary artery bypass graft is not recommended (Table 2 ). From the guidelines published in $2015,{ }^{39}$ IS is not recommended for routine prophylactic use in postoperative patients. Rather, early mobility and ambulation is recommended to reduce postoperative pulmonary complications and promote airway clearance.

\section{Why Have the Studies Been Negative?}

\section{Poor Methodology}

It is important to point out that poor study methodology complicates the ability to interpret studies of IS efficacy. This has been noted in the meta-analyses. ${ }^{32-37}$ Methodological flaws include imprecise procedure descriptions, lack of standardized outcomes, lack of appropriate control comparisons, underpowered studies, and an inability to isolate IS effects due to co-intervention. Meta-analyses of methodologically flawed data cannot resolve conflicting results. ${ }^{40}$

\section{Adherence}

Narayanan et $\mathrm{al}^{41}$ suggest that a major confounder in IS trials is the scarcity of data on patient adherence. They reported that only $16.6 \%$ of IS studies included mention of adherence rates, and the reported adherence data were not comprehensible due to omitted specific datasets, aggregated population values over the whole intervention period, arbitrary classifications of good adherence, and poorly kept patient-recorded adherence logs. Without accurate adherence data, valid assessment of IS efficacy cannot occur. The results of the study by Pantel et $a^{38}$ suggest that adherence is much less than prescribed. A therapy like IS that requires a very high level of adherence may not be practical.

\section{Perhaps IS Is Not Effective}

IS might well be one of those procedures that intuitively seems that it would improve pulmonary function but, in reality, does not affect important patient outcomes. In many hospitals, there is little patient supervision of IS after initial instruction, meaning that patient adherence is likely suboptimal. It seems that IS is a procedure for which patients lack motivation. The benefits of IS might be realized with closer supervision by health care providers, such as respiratory therapists or nurses. However, this is not practical in the U.S. health care delivery system. In patients at high risk for postoperative pulmonary complications, perhaps efforts should be directed toward optimizing pain control, early mobilization, and positive-pressure techniques such as $\mathrm{CPAP}^{42}$ or noninvasive ventilation. ${ }^{43}$ To determine whether there are specific patients for whom IS might be of value requires additional well-designed clinical trials of patients particularly prone to de-recruitment. For the specific population after bariatric surgery, the results of the study by Pantel et al ${ }^{38}$ suggests that IS is not effective. Physiologic studies, aiming at understanding the effects of IS, should be the key to design clinical studies 
including involving the right patients with the right IS maneuver.

\section{Summary}

Given the cost of implementing IS, the low adherence rate, and the lack of reported benefit, it is worth considering whether IS should continue to be prescribed. Despite the paucity of efficacy and adherence data, physicians often prescribe IS in an effort to do something to reduce postoperative pulmonary complications without knowing what exactly is being prescribed, the effort required of the patient, and the relatively low adherence rate. Given their expertise in working to optimize patients' postoperative pulmonary outcomes, respiratory therapists can play an integral role in educating providers about the dearth of evidence supporting IS. Further study is needed to determine which specific patient groups, if any, might benefit from IS.

\section{ACKNOWLEDGMENTS}

We acknowledge the following individuals for their contributions to the preparation of this manuscript: Grayson L Baird PhD for substantial contributions to conception and critically revising the manuscript for important intellectual content; Joshua Pangborn for substantial contributions to conception; Kristen Francoeur MSN RN for substantial contributions to conception; H Allethaire Cullen MSN RN for substantial contributions to conception and for critically revising the manuscript for important intellectual content; M Kelly Murphy MSN APRN for substantial contributions to conception and for critically revising the manuscript for important intellectual content; Katherine Paquette $\mathrm{PhD} \mathrm{RN}$ for substantial contributions to conception and for critically revising the manuscript for important intellectual content; Elizabeth Card MSN APN for critically revising the manuscript for important intellectual content; Susan Russell RN JD for critically revising the manuscript for important intellectual content; Barbara Riley DNP RN for critically revising the manuscript for important intellectual content; Paula Gellner MSN RN for critically revising the manuscript for important intellectual content; Samantha Norris RN for critically revising the manuscript for important intellectual content; Kevin Connors RRT CPFT for substantial contributions to conception and for critically revising the manuscript for important intellectual content; Jacqueline Barbaria RRT for substantial contributions to conception and for critically revising the manuscript for important intellectual content; Renee David NP for critically revising the manuscript for important intellectual content; Tina Calise DPT for critically revising the manuscript for important intellectual content; Katelyn DeCarlo DPT for critically revising the manuscript for important intellectual content; Saurabh Agarwal MD for substantial contributions to conception and for critically revising the manuscript for important intellectual content; Terrance T Healey MD for substantial contributions to conception and for critically revising the manuscript for important intellectual content; and Frank W Sellke MD for critically revising the manuscript for important intellectual content.

\section{REFERENCES}

1. Restrepo RD, Wettstein R, Wittnebel L, Tracy M. Incentive spirometry: 2011. Respir Care 2011;56(10):1600-1604.

2. Baker JP. Magnitude of usage of intermittent positive pressure breathing. Am Rev Respir Dis 1974;110(6 Pt 2):170-177.
3. Cheney FW Jr, Nelson EJ, Horton WG. The function of intermittent positive pressure breathing related to breathing patterns. Am Rev Respir Dis 1974;110(6 Pt 2):183-187.

4. Bartlett RH, Gazzaniga AB, Geraghty TR. Respiratory maneuvers to prevent postoperative pulmonary complications: a critical review. JAMA 1973;224(7):1017-1021.

5. Lederer DH, Van de Water JM, Indech RB. Which deep breathing device should the postoperative patient use? Chest 1980;77(5): 610-613.

6. Wilkins R. Lung expansion therapy. In: Wikins RL SJ, Kacmarek RM, editor. Egan's fundamentals of respiratory care, 9th ed. St. Louis: Mosby Elsevier; 2009:903-920.

7. Romanini W, Muller AP, Carvalho KA, Olandoski M, Faria-Neto JR, Mendes FL, et al. The effects of intermittent positive pressure and incentive spirometry in the postoperative of myocardial revascularization. Arq Bras Cardiol 2007;89(2):94-99,105-110.

8. Rafea A, Wagih K, Amin H, El-Sabagh R, Yousef S. Flow-oriented incentive spirometer versus volume-oriented spirometer training on pulmonary ventilation after upper abdominal surgery. Egypt J Brochoscopy 2009;3(2):110-118.

9. Craven JL, Evans GA, Davenport PJ, Williams RH. The evaluation of the incentive spirometer in the management of postoperative pulmonary complications. Br J Surg 1974;61(10):793-797.

10. Hall JC, Tarala RA, Tapper J, Hall JL. Prevention of respiratory complications after abdominal surgery: a randomised clinical trial. BMJ 1996;312(7024):148-152.

11. Bellet PS, Kalinyak KA, Shukla R, Gelfand MJ, Rucknagel DL. Incentive spirometry to prevent acute pulmonary complications in sickle cell diseases. N Engl J Med 1995;333(11):699-703.

12. Matte P, Jacquet L, Van Dyck M, Goenen M. Effects of conventional physiotherapy, continuous positive airway pressure and noninvasive ventilatory support with bilevel positive airway pressure after coronary artery bypass grafting. Acta Anaesthesiol Scand 2000;44(1):75-81.

13. Dohi S, Gold MI. Comparison of two methods of postoperative respiratory care. Chest 1978;73(5):592-595.

14. Stock MC, Downs JB, Gauer PK, Alster JM, Imrey PB. Prevention of postoperative pulmonary complications with CPAP, incentive spirometry, and conservative therapy. Chest 1985;87(2):151-157.

15. Kulkarni SR, Fletcher E, McConnell AK, Poskitt KR, Whyman MR. Pre-operative inspiratory muscle training preserves postoperative inspiratory muscle strength following major abdominal surgery: a randomised pilot study. Ann R Coll Surg Engl 2010;92(8):700-707.

16. Savci S, Sakinç S, Ince ID, Arikan H, Zehr C, Buran Y, Kuralay E. Active cycle of breathing techniques and incentive spirometer in coronary artery bypass graft surgery. Fizyoterapi Rehabilitasyon 2006; 17(2):61-69.

17. Celli BR, Rodriguez KS, Snider GL. A controlled trial of intermittent positive pressure breathing, incentive spirometry, and deep breathing exercises in preventing pulmonary complications after abdominal surgery. Am Rev Respir Dis 1984;130(1):12-15.

18. Dull JL, Dull WL. Are maximal inspiratory breathing exercises or incentive spirometry better than early mobilization after cardiopulmonary bypass? Phys Ther 1983;63(5):655-659.

19. Jung R, Wight J, Nusser R, Rosoff L. Comparison of three methods of respiratory care following upper abdominal surgery. Chest 1980; 78(1):31-35.

20. Renault JA, Costa-Val R, Rosseti MB, Houri Neto M. Comparison between deep breathing exercises and incentive spirometry after CABG surgery. Rev Bras Cir Cardiovasc 2009;24(2):165-172.

21. Schwieger I, Gamulin Z, Forster A, Meyer P, Gemperle M, Suter PM. Absence of benefit of incentive spirometry in low-risk patients undergoing elective cholecystectomy. A controlled randomized study. Chest 1986;89(5):652-656. 


\section{IS FOR Postoperative PUlmonary COMPLiCations}

22. Kundra P, Vitheeswaran M, Nagappa M, Sistla S. Effect of preoperative and postoperative incentive spirometry on lung functions after laparoscopic cholecystectomy. Surg Laparosc Endosc Percutan Tech 2010;20(3):170-172.

23. Lyager S, Wernberg M, Rajani N, Boggild-Madsen B, Nielsen L, Nielsen HC, et al. Can postoperative pulmonary conditions be improved by treatment with the Bartlett-Edwards incentive spirometer after upper abdominal surgery? Acta Anaesthesiol Scand 1979;23(4): 312-319.

24. O'Connor M, Tattersall MP, Carter JA. An evaluation of the incentive spirometer to improve lung function after cholecystectomy. Anaesthesia 1988;43(9):785-787.

25. Cassidy MR, Rosenkranz P, McCabe K, Rosen JE, McAneny D. I COUGH: reducing postoperative pulmonary complications with a multidisciplinary patient care program. JAMA Surg 2013;148(8): 740-745.

26. Ricksten SE, Bengtsson A, Soderberg C, Thorden M, Kvist H. Effects of periodic positive airway pressure by mask on postoperative pulmonary function. Chest 1986;89(6):774-781.

27. Jenkins SC, Soutar SA, Loukota JM, Johnson LC, Moxham J. Physiotherapy after coronary artery surgery: are breathing exercises necessary? Thorax 1989;44(8):634-639.

28. Oikkonen M, Karjalainen K, Kahara V, Kuosa R, Schavikin L. Comparison of incentive spirometry and intermittent positive pressure breathing after coronary artery bypass graft. Chest 1991;99(1):60-65.

29. Hall JC, Tarala R, Harris J, Tapper J, Christiansen K. Incentive spirometry versus routine chest physiotherapy for prevention of pulmonary complications after abdominal surgery. Lancet 1991; 337(8747):953-956

30. Agostini P, Naidu B, Cieslik H, Steyn R, Rajesh PB, Bishay E, et al. Effectiveness of incentive spirometry in patients following thoracotomy and lung resection including those at high risk for developing pulmonary complications. Thorax 2013;68(6):580-585.

31. Glover DW. The history of respiratory therapy: discovery and evolution. Bloomington, IN: AuthorHouse; 2010.

32. Thomas JA, McIntosh JM. Are incentive spirometry, intermittent positive pressure breathing, and deep breathing exercises effective in the prevention of postoperative pulmonary complications after upper abdominal surgery? A systematic overview and meta-analysis. Phys Ther 1994;74(1):3-10.

33. Overend TJ, Anderson CM, Lucy SD, Bhatia C, Jonsson BI, Timmermans $C$. The effect of incentive spirometry on postoperative pulmonary complications: a systematic review. Chest 2001;120(3): 971-978.
34. Carvalho CR, Paisani DM, Lunardi AC. Incentive spirometry in major surgeries: a systematic review. Rev Bras Fisioter 2011;15(5): 343-350.

35. Freitas ER, Soares BG, Cardoso JR, Atallah AN. Incentive spirometry for preventing pulmonary complications after coronary artery bypass graft. Cochrane Database Syst Rev 2012(9):CD004466.

36. do Nascimento Junior P, Modolo NS, Andrade S, Guimaraes MM, Braz LG, El Dib R. Incentive spirometry for prevention of postoperative pulmonary complications in upper abdominal surgery. Cochrane Database Syst Rev 2014(2):CD006058.

37. Agostini P, Singh S. Incentive spirometry following thoracic surgery: what should we be doing? Physiotherapy 2009;95(2):76-82.

38. Pantel H, Hwang J, Brams D, Schnelldorfer T, Nepomnayshy D. Effect of incentive spirometry on postoperative hypoxemia and pulmonary complications after bariatric surgery: a randomized clinical trial. JAMA Surg 2017;152(5):422-428.

39. Strickland SL, Rubin BK, Drescher GS, Haas CF, O'Malley CA, Volsko TA, et al. AARC clinical practice guideline: effectiveness of nonpharmacologic airway clearance therapies in hospitalized patients. Respir Care 2013;58(12):2187-2193.

40. Branson RD. The scientific basis for postoperative respiratory care. Respir Care 2013;58(11):1974-1984.

41. Narayanan AL, Hamid SR, Supriyanto E. Evidence regarding patient compliance with incentive spirometry interventions after cardiac, thoracic and abdominal surgeries: A systematic literature review. Can J Respir Ther 2016;52(1):17-26.

42. Squadrone V, Coha M, Cerutti E, Schellino MM, Biolino P, Occella $\mathrm{P}$, et al. Continuous positive airway pressure for treatment of postoperative hypoxemia: a randomized controlled trial. JAMA 2005; 293(5):589-595.

43. Jaber S, Lescot T, Futier E, Paugam-Burtz C, Seguin P, Ferrandiere $\mathrm{M}$, et al. Effect of noninvasive ventilation on tracheal reintubation among patients with hypoxemic respiratory failure following abdominal surgery: a randomized clinical trial. JAMA 2016;315(13):1345-1353.

44. Schwieger I, Gamulin Z, Forster A, Meyer P, Gemperle M, Suter PM. Absence of Benefit of Incentive Spirometry in Low-Risk Patients Undergoing Elective Cholecystectomy. Chest 1986;89(5):652656.

45. Lyager S, Wernberg M, Rajani N, et al. Can postoperative pulmonary conditions be improved by treatment with the Bartlett-Edwards incentive spirometer after upper abdominal surgery? Acta Anaesthesiol Scand 1979;23(4):312-319. 